\title{
Isolation and characterization of a new iturinic lipopeptide, mojavensin A produced by a marine-derived bacterium Bacillus mojavensis B0621A
}

\author{
Zongwang $\mathrm{Ma}^{1,2}$, Nan Wang ${ }^{1}$, Jiangchun $\mathrm{Hu}^{1}$ and Shujin Wang ${ }^{1}$ \\ Three lipopeptides were isolated by bioactivity-guided fractionation from the fermentation broth of Bacillus mojavensis \\ B0621A. A new iturinic lipopeptide, named mojavensin A (1), was tentatively characterized by 1D, 2D NMR and MS \\ spectroscopy, Marfey's method containing a novel peptide backbone of L-Asn 1, D-Tyr 2, D-Asn 3, L-Gln 4 , L-Pro 5, D-Asn 6 , L-Asn 7 \\ and an anteiso-type of the saturated $\beta$-fatty acid side chain. Compound 2 and 3 were tentatively identified as iso-C16 fengycin \\ $\mathrm{B}$ and anteiso-C17 fengycin B, respectively. These lipopeptides displayed dose-dependent antifungal activity against a broad \\ spectra of phytopathogens and were weakly antagonistic to Staphylococcus aureus. Moreover, they all revealed cytotoxic \\ activities against the human leukemia (HL-60) cell line. Mojavensin A, iso-C16 fengycin B, and anteiso-C17 fengycin \\ $B$ inhibited the growth of HL-60 with $\mathrm{IC}_{50}$ of 100,100 and $1.6 \mu \mathrm{M}$, respectively.
}

The Journal of Antibiotics (2012) 65, 317-322; doi:10.1038/ja.2012.19; published online 11 April 2012

Keywords: Bacillus mojavensis; fengycins; iturin; mojavensin

\section{INTRODUCTION}

Most Bacillus species have the ability to produce three families of lipopeptides, iturins, fengycins and surfactins, which show versatile functions in the biological control of fungal phytopathogens. ${ }^{1}$ Iturins, especially fengycins, have shown great potential in antagonistic activities in vitro. $^{2,3}$ Surfactins can enhance root colonization of beneficial Bacillus subtilis in the soil environment. ${ }^{4}$ Moreover, fengycins and surfactins can also induce plant system resistance., ${ }^{5,6}$ Plant-associated bacteria also have the potential to improve the growth of crops as plant growth-promoting rhizobacteria., ${ }^{7,8}$ These lipopeptides have important roles and there may be some synergistic effects in the interaction of plants, microorganisms and phytopathogens in the soil ecosystem.

Marine microorganisms have become a research focus because of their special natural products and unique and extreme ecosystem habitats, although their isolation and culture remains a difficult problem. ${ }^{9-11}$ Numerous new lipopeptides have been reported from marine habitat microorganisms recently. Cytotoxic mixirins A, B and $\mathrm{C}$ were isolated from a marine Bacillus sp. ${ }^{12}$ Tauramamide antagonistic to Enterococcus sp. was isolated from marine Brevibacillus laterosporus. ${ }^{13}$ Scopularides A and B possessing cytotoxic activities against pancreatic and colon tumor cell lines were isolated from a marine sponge-derived Scopulariopsis brevicaulis. ${ }^{14}$ An antifungal fengycin derivative with 6-Abu residue was found from a culture of
Bacillus amyloliquefaciens SH-B10. ${ }^{15}$ Bacillomycin D is a new antifungal iturin isolated from a sponge-derived $B$. subtilis. ${ }^{16}$ Mitsoamide revealing cytotoxic activities against NCI-H460 human lung tumor cells was isolated from a marine cyanobacterium Geitlerinema sp. ${ }^{17}$

In the present investigation, a potential biological control agent, Bacillus mojavensis B0621A, was isolated from Pinctada martensii in the South China Sea. In contrast, the type strain of B. mojavensis RO-H-1 was isolated from desert soil environment ${ }^{18}$ Lipopeptides produced by this strain were isolated, purified by HPLC system, elucidated by NMR spectroscopy and MS spectrometry techniques, and the antimicrobial activities were evaluated with paper disc-agar diffusion assay. ${ }^{19}$ The cytotoxic activities were based on 3-(4,5dimethylthiazol-2-yl)-2,5-diphenyltetrazolium bromide assay. ${ }^{20}$

\section{RESULTS AND DISCUSSION}

Compound $\mathbf{1}(22.6 \mathrm{mg}$ ) was purified from the fraction from vacuum flash chromatography (VFC; dichloromethane/methanol, $0: 100, \mathrm{v} / \mathrm{v}$ ) using the semi-preparative HPLC system described above, eluting with $75 \%$ methanol containing $0.05 \%$ trifluoroacetic acid (v/v)) at $17.35 \mathrm{~min}$. Compound $2(25.0 \mathrm{mg})$ and $3(30.0 \mathrm{mg})$ were purified from the fraction of VFC (dichloromethane/methanol, $70: 30, \mathrm{v} / \mathrm{v}$ ) using semi-preparative HPLC eluents of $80 \%$ methanol containing 
$0.05 \%$ trifluoroacetic acid (v/v) at $29.81 \mathrm{~min}$ and $42.17 \mathrm{~min}$, respectively.

\section{Structure elucidation}

Mojavensin A (1) was obtained as a white amorphous powder having a molecular formula of $\mathrm{C}_{50} \mathrm{H}_{77} \mathrm{~N}_{13} \mathrm{O}_{14}$ as found in the HR ESI MS spectrum, (see Supplementary Figure S7) which showed a $[\mathrm{M}+\mathrm{H}]^{+}$ ion peak at $\mathrm{m} / \mathrm{z} 1084.5674$ (calcd for 1084.5791) and a $[\mathrm{M}+\mathrm{Na}]^{+}$ ion peak at $m / z 1106.5605$ (calcd for 1106.5611 ), respectively. The ${ }^{1} \mathrm{H}$ NMR $\left(600 \mathrm{MHz}\right.$, DMSO- $\left.d_{6}\right)$ spectrum (see Supplementary Figure S1) showed $17 \mathrm{~N}$-bonded protons $(\delta$ 8.67-6.86) and seven $\alpha$-protons $(\delta 4.63-4.00)$ of peptide bonds, one para-substituted benzene ring $(\delta 6.65,7.01$, each $\mathrm{d}, J=8.4 \mathrm{~Hz}, 2 \mathrm{H})$, one long fatty acid chain $(\delta 1.42-1.06)$, and two terminal methyl see groups $(\delta 0.84, \mathrm{~m}, 6 \mathrm{H})$. The ${ }^{13} \mathrm{C}$ NMR $\left(150 \mathrm{MHz}, \mathrm{DMSO}-d_{6}\right)$ spectrum (see Supplementary Figure S2)showed the presence of 13 carbonyl groups $(\delta 170.5-174.6)$, one para-substituted benzene ring $(\delta 155.9,129.9$, $129.9,127.9,127.9,115.2), \alpha$-carbons of seven amino acids $(\delta 61.0-49.9)$, methylene carbons $(\delta 47.4-22.7)$, and two methyl carbons $(\delta 19.2,11.4)$, as well as the shape of two terminal methyl groups $(\delta 0.84, \mathrm{~m}, 6 \mathrm{H})$ of the ${ }^{1} \mathrm{H}$ NMR spectrum, indicating that the fatty acid chain was anteiso-type. ${ }^{21,22}$ Seven amino acids, including Asn $(4 \times)$, Gln $(1 \times)$, Pro $(1 \times)$ and Tyr $(1 \times)$, were identified on the basis of the ${ }^{1} \mathrm{H}_{-}{ }^{1} \mathrm{H}$ COSY (see Supplementary Figure S3), HSQC (see Supplementary Figure S4) and HMBC (see Supplementary Figure S5) experiments. The sequence of the amino-acid residues was determined by the ${ }^{1} \mathrm{H}_{-}{ }^{1} \mathrm{H}$ COSY, HMBC and ROESY (see Supplementary Figure S6) experiments, showing that that 1 contained the following sequence of amino acids: $\mathrm{Asn}_{1}, \mathrm{Tyr}_{2}, \mathrm{Asn}_{3}$, $\mathrm{Gln}_{4}, \mathrm{Pro}_{5}, \mathrm{Asn}_{6}, \mathrm{Asn}_{7}$ and $\beta$ amino acid with- $\left(\mathrm{CH}_{2}\right)_{9}\left(\mathrm{CH}_{3}\right) \mathrm{CH}_{2} \mathrm{CH}_{3}$ group as a side chain (Figure 1). The absolute configuration of the fatty acid chain of iturin A was determined to be R by CD spectrum 23 , whereas the configuration of the stereocenter in the fatty acid side chain was not determined in this study. From comprehensive

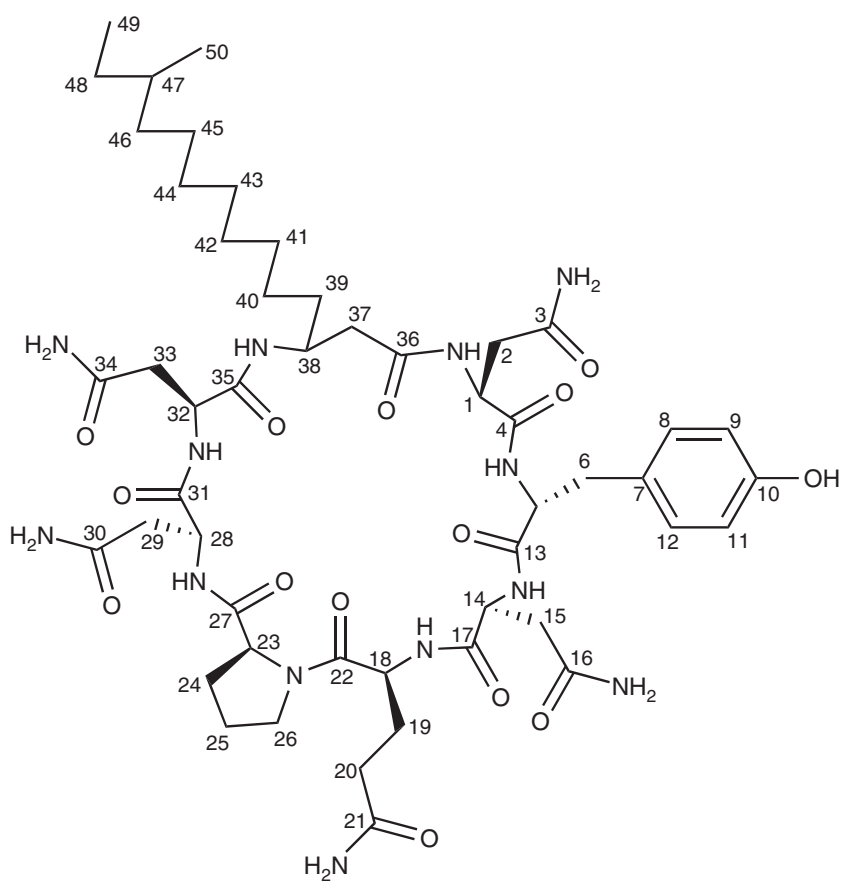

Figure 1 The structure of anteiso-C15 mojavensin A (1). consideration of all the results of 1, including analysis of Marfey's derivatives, the stereochemistry of these amino acids could be assumed as follows: L-Asn $1, \mathrm{D}-\mathrm{Tyr}_{2}, \mathrm{D}-\mathrm{Asn}_{3}, \mathrm{~L}-\mathrm{Gln}_{4}, \mathrm{~L}-\mathrm{Pro}_{5}, \mathrm{D}-\mathrm{Asn}_{6}$, $\mathrm{L}-\mathrm{Asn}_{7}$, respectively. In conclusion, 1 was a new compound belonging to the iturin family with amino acids composition of four Asn, and was named mojavensin A (Figure 1). The full assignment of ${ }^{1} \mathrm{H}$ and ${ }^{13} \mathrm{C}$ NMR chemical shifts of anteiso-C15 mojavensin A were based on the ${ }^{1} \mathrm{H}-{ }^{1} \mathrm{H}$ COSY, HSQC, HMBC and ROESY experiments (Table 1).

The ${ }^{13} \mathrm{C}$ NMR $\left(150 \mathrm{MHz}, \mathrm{DMSO}-d_{6}\right)$ data indicated that the fatty acid chain of 2 and 3 were iso- and anteiso-type, respectively (Supplementary Figure S8 and Figure S11). ${ }^{21}$ The full scan spectrum (MS1) of 2 showed singly and doubly-charged molecular ions at $m / z \quad 1491.99[\mathrm{M}+\mathrm{H}]^{+}$and $m / z \quad 746.42[\mathrm{M}+2 \mathrm{H}]^{2+}$, respectively (Supplementary Figure S9). The MS1 of 3 also showed singly and doubly-charged molecular ions at $m / z 1506.05[\mathrm{M}+\mathrm{H}]^{+}$ and $m / z 753.44[\mathrm{M}+2 \mathrm{H}]^{2+}$, respectively (Supplementary Figure S12). The doubly-charged molecular ion was chosen as the precursor ions for further tandem MS fragmentation. The fragments mainly contained b- and y-type ions (Figure 3 and Figure 4). The base peaks of 2 and 3 were $\mathrm{m} / z 1108.63$ and 1108.67 [M-fatty acid-Glu] ${ }^{+}$, respectively (Supplementary Figure S10 and Figure S13). Both 2 and 3 had the same b-type ions but different y ions, showing that the two compounds shared the same amino acids sequence of $\mathrm{Glu}_{1}, \mathrm{Orn}_{2}$, $\mathrm{Tyr}_{3}, \mathrm{Ile}_{4}, \mathrm{Tyr}_{5}, \mathrm{Gln}_{6}, \mathrm{Pro}_{7}, \mathrm{Val}_{8}, \mathrm{Glu}_{9}, \mathrm{Thr}_{10}$, but different fatty acid side chains. The stereochemistry of $\mathbf{2}$ and $\mathbf{3}$ were determined by Marfey's method successfully as follows: L-Glu, D-Orn 2, D-Tyr ${ }_{3}$, L-Ile 4 , L-Tyr 5, L-Gln 6 , L-Pro 7, D-Val 8, L-Glu 9, D-Thr 10 , respectively. Compound 2 was identified as iso-C16 fengycin B, whereas 3 was anteiso$\mathrm{C} 17$ fengycin B (Figure 2). The specific enantiomers of asparagine in $\mathbf{1}$ and of tyrosine in $\mathbf{2}$ and $\mathbf{3}$ have been positioned solely by analogy with the known members of these families.

\section{Antimicrobial and cytotoxic activity of three lipopeptides}

In this study, the potential anti-microorganism activities and the cytotoxicity to tumor cell lines of the three lipopeptides were tested. The three lipopeptides all showed activities to soil-borne phytopathogens and slight inhibition to Staphylococcus aureus, but no activity to Candida albicans. Moreover, they all showed weak cytotoxic activities against the human leukemia (HL-60) cell line. Mojavensin A (1), iso-C16 fengycin B (2) and anteiso-C17 fengycin $\mathrm{B}$ (3) inhibited the growth of HL-60 with $\mathrm{IC}_{50}$ of 100,100 and $1.6 \mu \mathrm{M}$, respectively.

Iturins, especially fengycins, display outstanding antibiotic activities. Anteiso-C15 mojavensin A (1) exhibited dose-dependent antifungal activity when the concentration was over $2 \mathrm{mg} \mathrm{ml}^{-1}$ for Valsa mali, Fusarium oxysporum f. sp. cucumerinum, and Fusarium verticillioides. Iso-C16 fengycin B (2) and anteiso-C17 fengycin B (3) demonstrated obvious concentration-dependent antifungal activities to the targeted filamentous phytopathogens (Table 2). Beyond the present knowledge, the antifungal activity of anteiso-C15 mojavensin A (1) was not as excellent as the other iturins, and the MIC $\left(2 \mathrm{mg} \mathrm{ml}^{-1}\right)$ of anteiso-C15 mojavensin A (1) was larger than for other iturins. Both the length of fatty acid chains and the different branches of iturins affected their antifungal activity. ${ }^{22}$ The structureactivity relationship of mojavensin A remains unclear and required further investigation. Two fengycins ( 2 and 3 ) had stronger antifungal abilities than iturin (1) over the results of this study.

Generally, F. verticillioides is a endophytic phytopathogen that produces fumonisin mycotoxins and has been recognized as a threat to maize, maize-containing products and other crops. ${ }^{24} \mathrm{~A} \mathrm{Leu}^{7}$ surfactin antagonistic to $F$. verticillioides has also been reported. ${ }^{25}$ 
Table $1{ }^{1} \mathrm{H}(600 \mathrm{MHz})$ and ${ }^{13} \mathrm{C}(150 \mathrm{MHz})$ NMR data assignments for mojavensin A (1) measured in DMSO- $d_{6}{ }^{\mathrm{a}}$

\begin{tabular}{|c|c|c|c|c|c|c|}
\hline Moiety & Position & $\delta_{C}$ & $\delta_{H}(J$ in $H z)$ & ${ }^{1} \mathrm{H}-{ }^{1} \mathrm{H} \operatorname{COS} Y$ & Selected HMBC & Selected ROESY \\
\hline \multirow[t]{5}{*}{$\mathrm{Asn}_{1}$} & 1 & 50.5 & $4.41 \mathrm{~m}$ & 2 & 2,4 & 2 \\
\hline & 2 & 36.7 & $2.20 \mathrm{dd}(5.4,6.0) / 2.29 \mathrm{~m}$ & & $1,4,3$ & \\
\hline & 4 & 173.3 & & & & \\
\hline & $1-\mathrm{NH}$ & & 7.79 d (5.4) & 1 & 1 & 1,38 \\
\hline & $3-\mathrm{NH}_{2}$ & & $6.91 \mathrm{~s} / 7.28 \mathrm{~s}$ & & 3 & \\
\hline \multirow{6}{*}{$\mathrm{Tyr}_{2}$} & 7 & 127.9 & & & & \\
\hline & 8,12 & 129.9 & $7.00 \mathrm{~d}(7.8)$ & & & $9,11, \delta_{\mathrm{H}} 9.16$ \\
\hline & 9,11 & 115.2 & $6.64 \mathrm{~d}(8.4)$ & & & $8,12, \delta_{\mathrm{H}} 9.16$ \\
\hline & 10 & 156 & & & & \\
\hline & 13 & 171.4 & & & & \\
\hline & $5-\mathrm{NH}$ & & $8.61 \mathrm{~d}(6.0)$ & 5 & 6 & 1,5 \\
\hline \multirow{2}{*}{$\mathrm{Asn}_{3}$} & $14-\mathrm{NH}$ & & $8.05 \mathrm{~d}(7.2)$ & 14 & $13,14,15$ & 5,14 \\
\hline & 16- $\mathrm{NH}_{2}$ & & $6.86 \mathrm{~s} / 7.21 \mathrm{~s}$ & & 16 & \\
\hline \multirow[t]{7}{*}{$\mathrm{Gln}_{4}$} & 18 & 49.9 & $4.44 \mathrm{~m}$ & 19 & & $19,20,26$ \\
\hline & 19 & 26.4 & $1.88 \mathrm{~m} / 1.94 \mathrm{~m}$ & & 20 & \\
\hline & 20 & 30.8 & $2.12 \mathrm{~m}$ & & 21,28 & \\
\hline & 21 & 174.6 & & & & \\
\hline & 22 & $171.1^{\mathrm{b}}$ & & & & \\
\hline & $18-\mathrm{NH}$ & & $7.17 \mathrm{~d}(7.8)$ & 18 & 18,19 & 14,18 \\
\hline & 21- $\mathrm{NH}_{2}$ & & $6.87 \mathrm{~s} / 7.27 \mathrm{~s}$ & & 21 & \\
\hline \multirow[t]{3}{*}{$\mathrm{PrO}_{5}$} & 23 & 61 & $4.14 \mathrm{t}$ & 24 & & 24 \\
\hline & 24 & 29.3 & $1.74 \mathrm{~m} / 2.11 \mathrm{~m}$ & 23 & $24,25,27$ & \\
\hline & 25 & 24.7 & $1.86 \mathrm{~m} / 1.96 \mathrm{~m}$ & 24 & & \\
\hline $\mathrm{Asn}_{6}$ & 30- $\mathrm{NH}_{2}$ & & $6.83 \mathrm{~s} / 7.36 \mathrm{~s}$ & & 30 & \\
\hline \multirow[t]{6}{*}{$\mathrm{Asn}_{7}$} & 32 & 50.4 & $4.63 \mathrm{~m}$ & 33 & 33 & 33 \\
\hline & 33 & 37.7 & $2.25 \mathrm{~m} / 2.68 \mathrm{~d}(4.9)$ & & 32,34 & \\
\hline & 34 & 171.1 & & & & \\
\hline & 35 & 171.1 & & & & \\
\hline & 32-NH & & $7.32 \mathrm{~d}(8.4)$ & 32 & & 28,32 \\
\hline & 34- $\mathrm{NH}_{2}$ & & $6.88 \mathrm{~s} / 7.18 \mathrm{~s}$ & & 34 & \\
\hline \multirow[t]{13}{*}{ fatty acid } & 36 & $171.3^{\mathrm{b}}$ & & & & \\
\hline & 37 & 42.2 & $2.31 \mathrm{~m}$ & 38 & & 38 \\
\hline & 38 & 46.1 & $3.94 \mathrm{~m}$ & 39 & & \\
\hline & 39 & 34.7 & $1.41 \mathrm{~m}$ & 40 & & \\
\hline & 40 & 25.6 & $1.12 \mathrm{~m} / 1.21 \mathrm{br} \mathrm{s}$ & 41 & & \\
\hline & $41-44$ & $28.8-29.3$ & $1.22 \mathrm{~m}$ & & & \\
\hline & 45 & 26.7 & $1.22 \mathrm{~m}$ & & & \\
\hline & 46 & 36.2 & $1.05 \mathrm{~m} / 1.14 \mathrm{~m}$ & & 45,50 & \\
\hline & 47 & 33.9 & $1.21 \mathrm{br} \mathrm{s}$ & 48 & 46 & \\
\hline & 48 & 29.1 & $1.06 \mathrm{~m} / 1.27 \mathrm{~m}$ & 49 & $46,47,49,50$ & \\
\hline & 49 & 11.4 & $0.80 \mathrm{~m}$ & & & \\
\hline & 50 & 19.2 & $0.83 \mathrm{~m}$ & 47 & & \\
\hline & 38-NH & & $7.10 \mathrm{~d}(9.0)$ & 38 & 38,39 & $32,37,38,39$ \\
\hline
\end{tabular}

aThe full assignments of ${ }^{1} \mathrm{H}$ and ${ }^{13} \mathrm{C}$ NMR chemical shifts of anteiso-C15 mojavensin A were based on ${ }^{1} \mathrm{H}-{ }^{1} \mathrm{H}$ COSY, HSQC, HMBC and ROESY experiments. bValues may be interchangeable within the same column. 
Fumonisin, especially fumonisin $B_{1}$, can increase the incidence of neural tube defects and inhibit eukaryotic protein synthesis, and it can also be a potential threat to human health..$^{26,27}$ In vitro antifungal experiments indicated that anteiso-C15 mojavensin A (1) and the two fengycins (2 and 3 ) had dose-dependent antagonistic activity against $F$. verticillioides and other phytopathogens. The interrelationships between fumonisin and lipopeptides should be further investigated.

The crude fingerprint of the lipopeptides (Supplementary Figure S15) indicated that B. mojavensis B0621A could secrete iturins, fengycins and surfactins. Surfactins produced by this strain had no antifungal activity after bioactive testing, but they may have had a critical role in the colonization of the bacteria in the soil-rhizosphere system. Our study has shown that B. mojavensis B0621A is a potential biological control agent, which can be applied in sustainable agricultural and crop protection.

\section{METHODS}

\section{General experimental procedures}

A semi-preparative HPLC system (Dionex U3000, Sunnyvale, CA, USA) was used in this study for analysis and further purification. One-dimensional and two-dimensional NMR spectroscopy $\left({ }^{1} \mathrm{H}-\mathrm{NMR},{ }^{13} \mathrm{C}-\mathrm{NMR},{ }^{1} \mathrm{H}-{ }^{1} \mathrm{H}\right.$ COSY, HSQC, HMBC, ROESY) were conducted with a Bruker AV600 spectrometer (Leipzig, Germany, 600 and $150 \mathrm{MHz}$ for ${ }^{1} \mathrm{H}$ and ${ }^{13} \mathrm{C}$ NMR, respectively), using DMSO- $d_{6}\left(\delta_{\mathrm{H}} 2.49\right.$ and $\delta_{\mathrm{C}} 39.6$, respectively) as internal references. The HR ESI MS experiments were performed with Bruker micro Q-TOF MS (Germany) and the Waters Micromass Q-TOF 2 (Manchester, UK) MS experiment was used to determine the sequence of the amino acids composition.

\section{Strains and fermentation conditions}

The B. mojavensis B0621A was isolated from the mantle of a pearl oyster P. martensii collected from Weizhou Island $\left(21^{\circ} 05^{\prime} \mathrm{N}, 109^{\circ} 11^{\prime} \mathrm{E}\right)$ in the South China Sea. The strain was identified by morphological, physiological and biochemical characteristics and the sequencing of 16S rDNA (see Supplementary Figure S14; GenBank accession number: JN585825). ${ }^{18}$ The culture

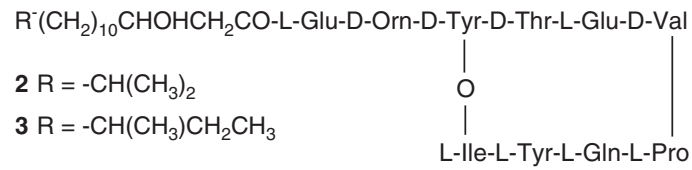

Figure 2 The structure of iso-C16 fengycin B (2) and anteiso-C17 fengycin $\mathrm{B}(3)$. conditions were based on Liu's medium ${ }^{28}$ with some modification as follows: sucrose $2.0 \%, \mathrm{NH}_{4} \mathrm{NO}_{3} \quad 0.2 \%, \mathrm{KH}_{2} \mathrm{PO}_{4} \quad 0.3 \%, \mathrm{Na}_{2} \mathrm{HPO}_{4} 1.0 \%$, $\mathrm{MgSO}_{4} \cdot 7 \mathrm{H}_{2} \mathrm{O} 0.02 \%$, yeast extracts $0.02 \%, \mathrm{CaCl}_{2} 0.7 \mu \mathrm{g}, \mathrm{MnSO}_{4} \cdot 4 \mathrm{H}_{2} \mathrm{O}$ $1 \mu \mathrm{g}$, and $\mathrm{pH}$ 7.0-7.2. The B. mojavensis $\mathrm{B} 0621 \mathrm{~A}$ was cultured in several $250-\mathrm{ml}$ flasks with $50 \mathrm{ml}$ of medium at $28^{\circ} \mathrm{C}$ for $20 \mathrm{~h}$, and were then used as the seed culture. The seed culture was then inoculated into 3-1 flasks each containing $1.5 \mathrm{l}$ of medium, and cultured for $48 \mathrm{~h}$ at a stirring rate of 180 r.p.m.

\section{Extraction, isolation and purification of lipopeptides}

The fermentation broth (241) of B. mojavensis B0621A was adjusted to $\mathrm{pH} 8.0$ with $4 \mathrm{~N} \mathrm{NaOH}$ and then centrifuged at $4000 \mathrm{~g}$ for $30 \mathrm{~min}$. The supernatant was then acidified to $\mathrm{pH} 2.0$ with $6 \mathrm{~N} \mathrm{HCl}$ and kept overnight at $4{ }^{\circ} \mathrm{C}$. The precipitate was collected by centrifugation at $4000 \mathrm{~g}$ for $30 \mathrm{~min}$, and rinsed with $\mathrm{HCl}(\mathrm{pH}$ 2.0) three times, followed by extraction of the residue with methanol three times. Finally, the solvent was evaporated under reduced pressure to yield $15.51 \mathrm{~g}$ of crude lipopeptides. The crude lipopeptides were eluted by dichloromethane/methanol (eight different ratios) using VFC over silica gel (600 800 mesh). Activity-guided fractionation and purification were conducted in this study using Fusarium oxysporum f. sp. cucumerinum as the targeted phytopathogen. Paper disc-agar diffusion assay established by Raahave is an efficient and simple method to evaluate the antibiotic activity. ${ }^{19}$ The antifungal fractions from VFC were further purified by a semi-preparative HPLC system using C18 YMC-Pack ODS-A column $(5 \mu \mathrm{m}, \varphi 10 \times 250 \mathrm{~mm})$ at a flow rate of $2.5 \mathrm{ml} \mathrm{min}^{-1}$ with UV detection at $220 \mathrm{~nm}$.

\section{Absolute stereochemistry of amino acid residues}

As described for Marfey's method, ${ }^{29}$ lipopeptides $(1 \mathrm{mg}$ ) were hydrolyzed with $6 \mathrm{~N} \mathrm{HCl}(1 \mathrm{ml})$ at $110^{\circ} \mathrm{C}$ for $24 \mathrm{~h}$, and were then dried in a vacuum. The hydrolyzes were added to $\mathrm{H}_{2} \mathrm{O}(50 \mu \mathrm{l}), 1 \%(\mathrm{w} / \mathrm{v})$ FDAA (Marfey's reagent, $100 \mu \mathrm{l})$ in acetone and $1 \mathrm{M} \mathrm{NaHCO}(20 \mu \mathrm{l})$. The mixture was heated at $37^{\circ} \mathrm{C}$ for $1 \mathrm{~h}$, after which $2 \mathrm{M} \mathrm{HCl}(10 \mu \mathrm{l})$ was added and the mixture was then evaporated to dryness. The residue was dissolved in $\mathrm{H}_{2} \mathrm{O}$ : DMSO $(\mathrm{v} / \mathrm{v}, 1: 1)(2 \mathrm{ml})$ and analyzed by reversed-phase HPLC (Luna 5UC18 Column, Phenomenex Inc., Torrance, CA, USA, $\varphi 4.6 \times 250 \mathrm{~mm}$, UV detection at $340 \mathrm{~nm}$, flow rate of $\left.1 \mathrm{ml} \mathrm{min}^{-1}\right)$ using a linear gradient $(10 \%$ acetonitrile containing $0.05 \%$ trifluoroacetic acid $(\mathrm{v} / \mathrm{v})$ to $50 \%$ acetonitrile within $60 \mathrm{~min}$ ). The final solution was analyzed by coinjection with standard L-/D-amino acids and compared with the Marfey's derivatives of authentic amino acids.

\section{In vitro antimicrobial spectrum and the cytotoxic activities determination}

Stock solutions were prepared by dissolving the purified lipopeptides in methanol to a concentration of $1 \mathrm{mg} \mathrm{ml}^{-1}$. Working solutions were made by twofold serial dilution of the stock solutions with methanol to test concentrations. Paper disc-agar diffusion assay was used to test the antimicrobial

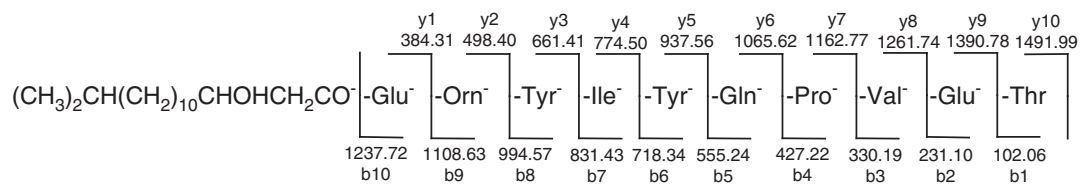

Figure 3 Positive ESI-Q-TOF MS2 fragmentation of iso-C16 fengycin B (2) resulting from precursor ion of $m / z 1491.99[\mathrm{M}+\mathrm{H}]^{+}$and $746.42[\mathrm{M}+2 \mathrm{H}]^{2+}$

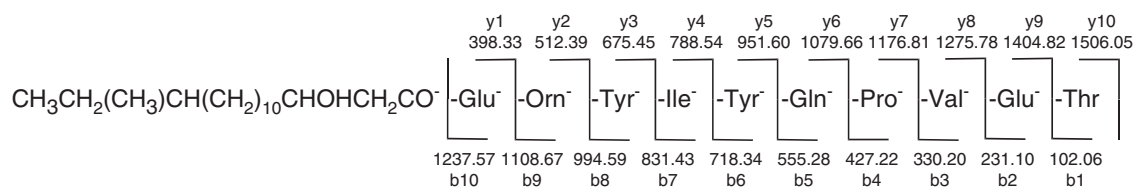

Figure 4 Positive ESI-Q-TOF MS2 fragmentation of anteiso-C17 fengycin B (3) resulting from precursor ion of $\mathrm{m} / \mathrm{z} 1506.05[\mathrm{M}+\mathrm{H}]^{+}$and 753.44 $[\mathrm{M}+2 \mathrm{H}]^{2+}$. 
Table 2 In vitro antifungal spectra of iso-C16 fengycin B (2) and anteiso-C17 fengycin B (3)

Inhibition zone $(\mathrm{mm})^{\mathrm{a}, \mathrm{b}}$

\begin{tabular}{|c|c|c|c|c|c|c|c|c|c|}
\hline \multirow[b]{2}{*}{ Phytopathogen (PSA, $\left.28^{\circ} \mathrm{C}\right)$} & \multirow[b]{2}{*}{ Time $^{\mathrm{c}}$} & \multicolumn{4}{|c|}{ Concentration of $\mathbf{2}\left(\mathrm{mg} \mathrm{ml}^{-1}\right)$} & \multicolumn{4}{|c|}{ Concentration of $\mathbf{3}\left(\mathrm{mg} \mathrm{ml}^{-1}\right)$} \\
\hline & & 0.125 & 0.250 & 0.500 & 1.000 & 0.125 & 0.250 & 0.500 & 1.000 \\
\hline Valsa mali & 60 & $8.31 \pm 0.24$ & $8.87 \pm 0.36$ & $9.69 \pm 0.32$ & $10.49 \pm 0.30$ & $6.57 \pm 0.08$ & $7.50 \pm 0.43$ & $9.30 \pm 1.15$ & $10.43 \pm 0.20$ \\
\hline Fusarium oxysporum f. sp. cucumerinum & 60 & $6.93 \pm 0.36$ & $7.03 \pm 0.43$ & $8.15 \pm 0.14$ & $8.99 \pm 0.39$ & $6.99 \pm 0.54$ & $7.45 \pm 0.57$ & $7.99 \pm 0.41$ & $9.09 \pm 0.61$ \\
\hline Fusarium oxysporum f. sp. vasinfectum & 60 & - & $7.20 \pm 0.26$ & $7.73 \pm 0.20$ & $9.77 \pm 0.88$ & $6.24 \pm 0.21$ & $7.13 \pm 0.53$ & $8.06 \pm 0.03$ & $8.50 \pm 0.35$ \\
\hline $\begin{array}{l}\text { Fusarium oxysporum f. sp. vasinfectum. } \\
\text { SF } 2\end{array}$ & 72 & $6.14 \pm 0.18$ & $6.79 \pm 0.18$ & $7.70 \pm 0.09$ & $9.77 \pm 0.88$ & $6.25 \pm 0.34$ & $6.78 \pm 0.33$ & $8.07 \pm 0.18$ & $8.55 \pm 0.25$ \\
\hline Fusarium solani SF 130 & 60 & $5.43 \pm 0.16$ & $7.19 \pm 0.13$ & $7.85 \pm 0.52$ & $9.84 \pm 0.47$ & $6.07 \pm 0.19$ & $7.83 \pm 0.97$ & $8.78 \pm 0.43$ & $9.98 \pm 0.50$ \\
\hline Botryosphaeria berengriana f. sp. piricola & 48 & $7.08 \pm 0.29$ & $8.37 \pm 0.42$ & $9.49 \pm 0.50$ & $10.10 \pm 0.27$ & $7.17 \pm 0.11$ & $7.44 \pm 0.34$ & $8.49 \pm 0.24$ & $8.98 \pm 0.59$ \\
\hline Botrytis cicrea & 60 & $8.75 \pm 0.62$ & $10.18 \pm 0.33$ & $10.71 \pm 0.21$ & $11.88 \pm 0.47$ & $7.95 \pm 0.64$ & $8.90 \pm 0.24$ & $9.85 \pm 0.50$ & $11.65 \pm 1.06$ \\
\hline Rhizoctonia solani J. G. Kühn & 24 & - & - & $6.65 \pm 0.26$ & $8.37 \pm 0.20$ & - & - & - & $6.63 \pm 0.54$ \\
\hline Fusarium solani & 60 & $5.65 \pm 0.34$ & $8.47 \pm 0.38$ & $9.19 \pm 0.32$ & $9.73 \pm 0.39$ & $5.23 \pm 0.10$ & $6.47 \pm 0.19$ & $7.17 \pm 0.61$ & $9.71 \pm 0.43$ \\
\hline Rhizoctonia solani & 60 & - & $6.53 \pm 0.13$ & $6.87 \pm 0.36$ & $7.92 \pm 0.44$ & - & $5.17 \pm 0.19$ & $6.47 \pm 0.40$ & $7.60 \pm 0.33$ \\
\hline Valsa ceratosperma & 24 & $7.57 \pm 0.41$ & $8.23 \pm 0.14$ & $9.00 \pm 0.14$ & $10.31 \pm 0.19$ & $7.19 \pm 0.27$ & $7.30 \pm 0.31$ & $7.89 \pm 0.16$ & $9.19 \pm 0.43$ \\
\hline Fusarium oxysporum f. sp. Cucumis melo L. & 48 & $5.25 \pm 0.38$ & $6.39 \pm 0.59$ & $8.03 \pm 0.19$ & $9.26 \pm 0.07$ & $5.79 \pm 0.26$ & $6.27 \pm 0.26$ & $7.99 \pm 0.27$ & $9.55 \pm 0.26$ \\
\hline Fusarium graminearum & 60 & $7.22 \pm 0.24$ & $8.25 \pm 0.17$ & $9.30 \pm 0.25$ & $11.03 \pm 0.04$ & $5.81 \pm 0.14$ & $7.72 \pm 0.81$ & $9.10 \pm 0.16$ & $10.69 \pm 0.70$ \\
\hline Bipolaris maydis & 72 & - & - & - & $6.95 \pm 0.08$ & - & - & - & $8.51 \pm 0.17$ \\
\hline Colletotrichum orbiculare & 60 & $9.11 \pm 0.06$ & $10.54 \pm 0.57$ & $11.20 \pm 0.02$ & $12.48 \pm 0.46$ & $9.88 \pm 0.50$ & $10.57 \pm 0.46$ & $11.07 \pm 0.24$ & $11.36 \pm 0.92$ \\
\hline Fusarium verticillioides ${ }^{\mathrm{d}}$ & 72 & - & $6.59 \pm 0.39$ & $7.01 \pm 0.20$ & $7.93 \pm 0.28$ & - & $6.09 \pm 0.67$ & $6.90 \pm 0.28$ & $7.73 \pm 0.22$ \\
\hline Fusarium verticillioides ${ }^{\mathrm{e}}$ & 60 & - & $6.23 \pm 0.19$ & $8.33 \pm 0.47$ & $9.55 \pm 0.52$ & - & $6.72 \pm 0.30$ & $7.32 \pm 0.55$ & $8.67 \pm 0.20$ \\
\hline
\end{tabular}

aThe data represented radius (mean \pm s.d., $\mathrm{mm}$ ) of antifungal zone.

Each paper (diameter: $10 \mathrm{~mm})$ contained $10 \mu \mathrm{l}$ volume, the control only contained methanol $(10 \mu \mathrm{l})$.

${ }^{\mathrm{C}}$ The reaction time $(\mathrm{h})$ between antibiotic and phytopathogens.

${ }^{\mathrm{d}}$ An endophytic phytopathogen isolated from Arctium lappa L.

eAn endophytic phytopathogen of Gossypium spp.

activity. Each concentration was conducted in triplicate and independently, and the diameters of inhibition zones were measured with a slide gauge. Then, the human leukemia (HL-60) cell line was used as a model to evaluate the cytotoxicity of lipopeptides based on the 3-(4,5-dimethylthiazol-2-yl)-2,5diphenyltetrazolium bromide assay.

\section{ACKNOWLEDGEMENTS}

This work was supported by Grants from the National High Technology Research and Development Program of China (863 Program) (No. 2007AA09Z417, 2011AA09070404), Chinese Academy of Sciences Innovation Projects (No. KSCX2-EW-G-16), the National Science \& Technology Pillar Program (No. 2011BAE06B04). We also acknowledge Ms Ping Li of the National Center of Biomedical Analysis at Academy of Military Medical Sciences for assistance in MS experiments.

1 Ongena, M. \& Jacques, P. Bacillus lipopeptides: versatile weapons for plant disease biocontrol. Trends Microbio. 16, 115-125 (2008).

2 Romero, D. et al. The iturin and fengycin families of lipopeptides are key factors in antagonism of Bacillus subtilis toward Podosphaera fusca. Mol. Plant Microbe In. 20, 430-440 (2007).

3 Vanittanakom, N., Loeffler, W., Koch, U. \& Jung, G. Fengycin-a novel antifungal lipopeptide antibiotic produced by Bacillus-Subtilis F-29-3. J. Antibiot. 39, 888-901 (1986).

4 Vivanco, J. M., Bais, H. P. \& Fall, R. Biocontrol of Bacillus subtilis against infection of Arabidopsis roots by Pseudomonas syringae is facilitated by biofilm formation and surfactin production. Plant Physiol. 134, 307-319 (2004).

5 Ongena, M. et al. Surfactin and fengycin lipopeptides of Bacillus subtilis as elicitors of induced systemic resistance in plants. Environ. Microbio. 9, 1084-1090 (2007).

6 Jourdan, E. et al. Insights into the defense-related events occurring in plant cells following perception of surfactin-type lipopeptide from Bacillus subtilis Mol. Plant Microbe In. 22, 456-468 (2009).
7 Compant, S., Clement, C. \& Sessitsch, A. Plant growth-promoting bacteria in the rhizoand endosphere of plants: their role, colonization, mechanisms involved and prospects for utilization. Soil Biol. Biochem. 42, 669-678 (2010).

8 Raaijmakers, J. M., Paulitz, T. C., Steinberg, C., Alabouvette, C. \& Moenne-Loccoz, Y. The rhizosphere: a playground and battlefield for soilborne pathogens and beneficial microorganisms. Plant Soil. 321, 341-361 (2009).

9 Molinski, T. F., Dalisay, D. S., Lievens, S. L. \& Saludes, J. P. Drug development from marine natural products. Nat. Rev. Drug Discov. 8, 69-85 (2009).

10 Joint, I., Muhling, M. \& Querellou, J. Culturing marine bacteria-an essential prerequisite for biodiscovery. Microb. Biotechnol. 3, 564-575 (2010).

11 Das, S., Lyla, P. S. \& Khan, S. A. Marine microbial diversity and ecology: importance and future perspectives. Curr. Sci. India. 90, 1325-1335 (2006).

12 Zhang, H. L., Hua, H. M., Pei, Y. H. \& Yao, X. S. Three new cytotoxic cyclic acylpeptides from Marine Bacillus sp. Chem. Pharm Bull. 52, 1029-1030 (2004).

13 Andersen, R. J. et al. Tauramamide, a lipopeptide antibiotic produced in culture by Brevibacillus laterosporus isolated from a marine habitat: Structure elucidation and synthesis. J. Nat. Prod. 70, 1850-1853 (2007).

14 Imhoff, J. F., Yu, Z. G., Lang, G., Kajahn, I. \& Schmaljohann, R. Scopularides A and B, cyclodepsipeptides from a marine sponge-derived fungus Scopulariopsis brevicaulis. J. Nat. Prod. 71, 1052-1054 (2008).

15 Chen, L. L., Wang, N., Wang, X. M., Hu, J. C. \& Wang, S. J. Characterization of two anti-fungal lipopeptides produced by Bacillus amyloliquefaciens SH-B10. Bioresour. Technol. 101, 8822-8827 (2010).

16 Oleinikova, G. K. et al. Bacillomycin d from the marine isolate of Bacillus subtilis KMM 1922. Chem. Nat. Compd. 41, 461-464 (2005).

17 Gerwick, W. H., Andrianasolo, E. H. \& Goeger, D. Mitsoamide: a cytotoxic linear lipopeptide from the Madagascar marine cyanobacterium Geitlerinema sp. Pure Appl. Chem. 79, 593-602 (2007).

18 Roberts, M. S., Nakamura, L. K. \& Cohan, F. M. Bacillus mojavensis SP-NOV, distinguishable from Bacillus-subtilis by sexual isolation, divergence in DNA-sequence, and differences in fatty-acid composition. Int. J. Syst. Bacteriol. 44, 256-264 (1994).

19 Raahave, D. Paper disk-agar diffusion assay of penicillin in the presence of streptomycin. Antimicrob. Agents Chemother. 6, 603-605 (1974).

20 Mosmann, T. Rapid colorimetric assay for cellular growth and survivalapplication to proliferation and cyto-toxicity assays. J. Immunol. Methods. 65, 5563 (1983). 
21 Lin, S. C., Minton, M. A., Sharma, M. M. \& Georgiou, G. Structural and Immunological Characterization of a Biosurfactant Produced by Bacillus-Licheniformis Jf-2. Appl. Environ. Microb. 60, 31-38 (1994).

22 Eshita, S. M., Roberto, N. H., Beale, J. M., Mamiya, B. M. \& Workman, R. F. Bacillomycin $L(C)$ a new antibiotic of the iturin group-isolations, structures, and antifungal activities of the congeners. J. Antibiot. 48, 1240-1247 (1995).

23 Nagai, U., Besson, F. \& Peypoux, F. Absolute-configuration of an iturinic acid as determined by CD spectrum of its DNP-para-methoxyanilide. Tetrahedron Lett. 25, 2359-2360 (1979).

24 Riley, R. T., Norred, W. P. \& Bacon, C. W. Fungal toxins in foods-recent concerns. Annu. Rev. Nutr. 13, 167-189 (1993).
25 Snook, M. E., Mitchell, T., Hinton, D. M. \& Bacon, C. W. Isolation and Characterization of Leu(7)-surfactin from the endophytic bacterium Bacillus mojavensis RRC 101, a biocontrol agent for Fusarium verticillioides. J. Agric. Food Chem. 57, 4287-4292 (2009).

26 Sashidhar, R. B. \& Karuna, R. The mycotoxin Fumonisin B-1 inhibits eukaryotic protein synthesis: in vitro and in vivo studies. Mycopathologia. 165, 37-49 (2008).

27 Thibault, N., Burgat, V. \& Guerre, P. Fumonisins: Properties, sources and toxicity. Rev. Med. Vet-Toulouse. 148, 369-388 (1997).

28 Liu, X. Y., Yang, S. Z. \& Mu, B. Z. Isolation and characterization of a C-12-lipopeptide produced by Bacillus subtilis HSO 121. J. Pept. Sci. 14, 864-875 (2008).

29 Marfey, P. Determination of D-amino acids.2. Use of a bifunctional reagent, 1,5difluoro-2,4-dinitrobenzene. Carlsberg Res. Commun. 49, 591-596 (1984).

Supplementary information of this paper is available at The Journal of Antibiotics website (http://www.nature.com/ja) 